\title{
CB Research Square \\ Coronavirus Disease 2019 Induced Inflammatory Response are Associated with Changes in Lipid Profiles
}

\section{Chuanwei Li}

Third Military Medical University Daping Hospital and Research Institute of Surgery

\section{Wen Zhang}

Xinqiao Hospital

\section{Chunmei Xu}

Third Military Medical University Daping Hospital and Research Institute of Surgery

\section{Hu Tan}

Xinqiao Hospital

\section{Guoqiang Cao}

Third Military Medical University Daping Hospital and Research Institute of Surgery

\section{Li Li}

Third Military Medical University Daping Hospital and Research Institute of Surgery

\section{Qidi Sun}

Third Military Medical University Daping Hospital and Research Institute of Surgery

\section{Gengze Wu}

Third Military Medical University Daping Hospital and Research Institute of Surgery

\section{Mingdong $\mathrm{Hu}$ \\ Xinqiao Hospital}

\section{Shuang Wu}

Wuhan Jinyintan Hospital

Qi Li

Xinqiao Hospital

\section{Guansong Wang}

Xinqiao Hospital

\section{Xiaohua Zhang}

Third Military Medical University Daping Hospital and Research Institute of Surgery

Chunyu Zeng ( $\nabla$ chunyuzeng007@163.com)

Third Military Medical University Southwest Hospital Department of Pathology https://orcid.org/0000-0003-3309-160X

\section{Research article}

Keywords: Covid-19, Lipid, Lipoprotein, Cytokine, Inflammation

Posted Date: September 8th, 2020

DOI: https://doi.org/10.21203/rs.3.rs-64766/v1

License: () (i) This work is licensed under a Creative Commons Attribution 4.0 International License. Read Full License 


\section{Abstract}

Background: Previous studies have found some evidence of association between changes in lipids and lipoprotein and viral pneumonia. No data are available about the effect of coronavirus disease 2019 (Covid-19) on lipids. The aim of this study was to investigate the relationships between lipid profiles and inflammation markers among patients with Covid-19.

Methods: In this retrospective analysis, Covid-19 patients in Jin-yin-tan Hospital and healthy individuals from Daping Hospital were enrolled. The clinical and biochemical characteristics of Covid-19 patients and healthy controls were compared. We correlated lipid parameters to disease severity and inflammatory markers. The severity of Covid-19 for all patients were stipulated according to the diagnostic and treatment guideline for Covid-19 issued by Chinese National Health Committee (the 7th edition).

Results: A total of 242 Covid-19 patients and 242 sex-age matched controls were enrolled. Compared with controls, Covid-19 patients had lower lymphocyte counts as well as total cholesterol (TC), high density lipoprotein (HDL-C), low density lipoprotein cholesterol (LDL-C), non-high density lipoprotein cholesterol (non-HDL-C) and apoA-l levels on admission. Whereas apolipoprotein B (apoB) and apoB/apoA-I ratio were slightly higher in patients with Covid-19. There was no difference in lipid levels between the moderate and severe groups. The total lymphocytes were weakly positively associated with TC, LDL-C and apoA-I.

Conclusion: Patients with Covid-19 are associated with decreased lipid and lipoprotein levels. Covid-19 infection induced inflammation response and cytokine storm were associated with a shift of lipids, lipoproteins toward a more atherogenic lipid profile.

\section{Background}

The outbreak of novel coronavirus disease 2019 (Covid-19) is evolving rapidly in China and worldwide since December 2019 and attracted extensive attention around the world. The World Health Organization (WHO) has already declared Covid-19 a public health emergency of international concern. As of Aug 17, 2020, a total of 21, 979,927 laboratory-confirmed cases had been documented globally [1]. We and my colleagues have worked in Wuhan as emergency medical aid for about three months to control the prevalence. All population groups were generally susceptible to the virus, the clinical manifestations of Covid-19 are heterogeneous, most patients are asymptomatic or have mild symptoms and with good prognosis. However, some patients deteriorate rapidly in the later stages or in the recovery process due to vital complications, including shock, adult respiratory distress syndrome and organ failure and the mortality increased sharply in critical patients [2]. Some evidence shows that such an event has been closely related to the virally driven proinflammatory cytokine storm and extrapulmonary multiple-organ damage in their bodies [3]. The intrinsic antiinflammatory properties act as the first defense to excessive cytokine production. Lipids and lipoproteins are an integral part of the innate and adaptive immune system and play an important role in inflammatory response [4]. In addition, almost all lipid parameters have been found to be significantly re-arranged during acute virus infection, including Epstein-Barr virus (EBV), cytomegalovirus (CMV) and others [5-6]. The changes in lipoproteins especially the high density lipoprotein (HDL) and apolipoprotein A-I (apoA-I) contribute to disease pathogenesis in respiratory disorders [7]. The pathogenicity and infectiosity of Covid-19 were distinct from previous respiratory infectious virus diseases. There are no data on possible alterations in serum lipid profile in patients with Covid19. In the present study, we investigated the lipid levels with laboratory confirmed Covid-19 who were admitted to Wuhan Jin-yin-tan Hospital and sex-age matched healthy controls in Chongqing Daping Hospital. We explore the relationship between lipid and lipoprotein levels and the inflammatory markers of Covid-19 patients.

\section{Methods}

\section{Study design and participants}

We obtained the medical records for hospitalized patients in Jin-yin-tan Hospital, a hospital for adults (aged $\geq 14$ years) specialising in infectious diseases with laboratory-confirmed moderate or severe Covid-19 patients, as reported to the National Health Commission of China between January 29, 2020 and February 27, 2020. All patients involved in this study were living in Wuhan during the outbreak period of Covid-19. A confirmed case of Covid-19 was defined as a positive result on real-time reversetranscriptase polymerase-chain-reaction (RT-PCR) assay of nasal swab specimens. 
We enrolled 242 age and sex matched healthy individuals who received regular health examination in the Medical Examination Center of Daping Hospital without documented acute infectious disease as control population. No study individual was receiving any hypolipidaemic agents or had any clinical or laboratory evidence of any disease known to affect lipid metabolism, such as neoplasia, renal or liver dysfunction, and hypo- or hyperthyroidism. The Ethics Commission of Third Military Medical University approved this study. Written informed consent was waived due to the rapid emergence of this infectious disease.

\section{Data collection}

We extracted the clinical symptoms, and laboratory findings on admission from electronic medical records. Laboratory assessments consisted of a complete blood count, blood chemical analysis, fasting glucose, coagulation testing, assessment of liver and renal function, fasting lipoprotein levels, and measures of C-reactive protein (CRP), procalcitonin (PCT), interleukin-6 (IL-6) within 48 hours after admission. Patients were classified as having moderate or severe Covid-19 based on the diagnostic and treatment guideline for Covid-19 issued by Chinese National Health Committee (the 7th edition) at the time of admission [8]. Data were entered into a computerized database and cross-checked.

\section{Statistical Analysis}

The categorical variables are summarized as counts and percentages. Mean values and percentages were compared among different groups by $\chi 2$ tests. The Kolmogorov-Smirnov test was used to evaluate whether each variable followed a Gaussian distribution. Continuous variables not following a Gaussian distribution are expressed as median (interquartile range, IQR) and were compared between two groups using the Mann-Whitney $U$ test. Correlations between lipoprotein levels and the inflammatory markers were tested using Spearman correlation coefficient (rho). All data were analyzed using IBM SPSS Statistics version 19.0 (SPSS, Chicago, IL, USA). $P<0.05$ (two-tailed) was considered to be statistically significant.

\section{Results}

\section{Characteristics of study population}

A total of 283 patients were included in the Covid- 19 hospital study, 2 cases died within 12 hours of admission, while 39 cases missing part or all cholesterol measurements, leaving 242 patients available for analysis. The clinical characteristics of the 242 Covid-19 patients are shown in Table 1. According to the guidelines for diagnosis and management of Covid-19 (7th edition) issued by the National Health Commission of China, patients with percutaneous oxygen saturation of $93 \%$ or lower or respiratory rates of $30 / \mathrm{min}$ or greater on room air who required high-flow nasal cannula or noninvasive mechanical ventilation using the bilevel positive airway pressure mode to correct hypoxemia, were classified as severe group, whereas patients not reaching the criteria for severe Covid-19 were considered as moderate. ${ }^{8}$ On admission, the degree of severity of Covid-19 was categorized as moderate in 173 patients and severe in 69 patients. The median age of the patients was 63.0 years (IQR 53.0 to 68.3), there was no significant differences in median age among the moderate group (63.0, IQR 52.9-69.0) and the severe group (64.0, IQR 53.5-68.0). 
Table 1

Demographics and baseline characteristics of patients

\begin{tabular}{|lllll|}
\hline & $\begin{array}{l}\text { All patients } \\
(\mathbf{n = 2 4 2})\end{array}$ & $\begin{array}{l}\text { Non severe } \\
\text { group } \\
(\mathbf{n = 1 7 3 )}\end{array}$ & $\begin{array}{l}\text { Severe group } \\
(\mathbf{n = 6 9 )}\end{array}$ & $\begin{array}{l}\text { Pfor the comparison of moderate and } \\
\text { severe patients }\end{array}$ \\
\hline Age (years) & $63.0(53.0-68.3)$ & $63.0(52.9-69.0)$ & $\begin{array}{l}64.0(53.5- \\
68.0)\end{array}$ & NS \\
\hline Male (\%) & $133 / 242(55.0 \%)$ & $96 / 173(55.5 \%)$ & $37 / 69(53.6 \%)$ & NS \\
\hline comorbidities & & & & \\
\hline Hypertension & $76 / 242(31.4 \%)$ & $42 / 173(24.3 \%)$ & $34 / 69(49.3 \%)$ & $<0.001$ \\
\hline Known history of diabetes & $61 / 242(25.2 \%)$ & $35 / 173(20.2 \%)$ & $26 / 69(27.7 \%)$ & $<0.01$ \\
\hline Coronary heart disease & $12 / 242(5.0 \%)$ & $7 / 173(4.0 \%)$ & $5 / 69(7.2 \%)$ & NS \\
\hline symptoms & & & & NS \\
\hline Fever & $191 / 242(78.9 \%)$ & $133 / 173(76.9 \%)$ & $58 / 69(84.6 \%)$ & NS \\
\hline Cough & $169 / 242(69.8 \%)$ & $120 / 173(69.4 \%)$ & $49 / 69(71.0 \%)$ & $<0.001$ \\
\hline Dyspnea & $104 / 242(43.0 \%)$ & $59 / 173(34.1 \%)$ & $45 / 69(65.2 \%)$ & NS \\
\hline $\begin{array}{l}\text { Days from illness onset to } \\
\text { admission }\end{array}$ & $11.5(9.0-15.0)$ & $11.0(8.5-15.0)$ & $\begin{array}{l}12.0(9.3- \\
16.0)\end{array}$ & \\
\hline Data are expressed as median (interquartile range) & & & \\
\hline
\end{tabular}

Fever was the most dominant symptom, accounting $78.9 \%$ of the patients on admission, followed by cough (169 [69.8\%] of 242 patients), dyspnea (104 [43.0\%]) and others (myalgia, haemoptysis, diarrhoea). The proportion of dyspnea in the severe group (45[65.2\%] of 69 patients) differs significantly from that of the moderate group (59[34.1\%] of 173 patients). Among the overall population, $49.6 \%$ had at least one coexisting illness (e.g., hypertension, diabetes and coronary heart disease). Moreover, the presence of any coexisting illness was more common among the severe patients than the moderate group.

\section{Biochemical measurements and lipid profiles}

Another 242 sex and age matched healthy controls without acute infection were included in this study, the median age of the patients was 59.0 years (IQR 53.0 to 68.0) (Table 2). On admission, the lymphocyte counts were significantly lower in the Covid-19 patients (1.1, IQR 0.8-1.4 $10 \mathrm{Q} / \mathrm{L})$ than the control (1.4, IQR 1.0-1.8*10区/L). There was no significant difference in white blood cell and neutrocyte counts among the two groups. The Covid-19 patients had elevated levels of C-reactive protein (CRP). The concentrations of total cholesterol (TC), high density lipoprotein (HDL-C), low density lipoprotein cholesterol (LDL-C), non-high density lipoprotein cholesterol (non-HDL-c) as well as apoA-I were all reduced, whereas apolipoprotein B (apoB) and apoB/apoA-I ratio were slightly increased in patients with Covid-19 compared with controls. Moreover, the severe group had more prominent laboratory abnormalities, including lymphocytopenia, leucocytosis and granulocytosis than the moderate group and higher inflammatory markers (CRP and IL-6). Although we found that lipids and lipoproteins were significantly changed in Covid-19 patients compared with healthy subjects, no significant difference was observed regarding the levels of TC, triglyceride (TG), HDL-C, LDL-C, non-HDL-C, apoA and apoB in the severe patients compared with the moderate cases (Table 2). 
Table 2

Laboratory findings of patients infected with Covid-19 on admission to hospital

\begin{tabular}{|c|c|c|c|c|c|c|c|}
\hline & $\begin{array}{l}\text { Normal } \\
\text { Range }\end{array}$ & $\begin{array}{l}\text { Control } \\
(n=242)\end{array}$ & $\begin{array}{l}\text { All patients } \\
(n=242)\end{array}$ & $\begin{array}{l}P \text { for the } \\
\text { comparison } \\
\text { of patients } \\
\text { with } \\
\text { controls }\end{array}$ & $\begin{array}{l}\text { Non severe } \\
\text { group } \\
(n=173)\end{array}$ & $\begin{array}{l}\text { Severe group } \\
(n=69)\end{array}$ & $\begin{array}{l}P \text { for the } \\
\text { comparison } \\
\text { of } \\
\text { moderate } \\
\text { and severe } \\
\text { patients }\end{array}$ \\
\hline Age (years) & NA & $59.0(53.0-68.0)$ & $63.0(53.0-68.3)$ & NS & $\begin{array}{l}63.0(52.9- \\
69.0)\end{array}$ & $\begin{array}{l}64.0(53.5- \\
68.0)\end{array}$ & NS \\
\hline Male (\%) & NA & $135 / 242(55.8 \%)$ & $133 / 242(55.0 \%)$ & NS & $96 / 173(55.5 \%)$ & $37 / 69(53.6 \%)$ & NS \\
\hline $\begin{array}{l}\text { WBC } \\
\left(\star^{*} 108 / L\right)\end{array}$ & $\begin{array}{l}3.5- \\
9.5\end{array}$ & $6.2(5.2-7.3)$ & $5.8(4.6-7.7)$ & NS & $5.5(4.2-7.0)$ & $\begin{array}{l}6.69(5.2- \\
11.5)\end{array}$ & $<0.001$ \\
\hline $\begin{array}{l}\text { NEUT } \\
(* 10 \otimes / L)\end{array}$ & $\begin{array}{l}1.8- \\
6.3\end{array}$ & $4.2(3.2-4.1)$ & $4.0(2.8-5.8)$ & NS & $3.8(2.7-5.1)$ & $4.9(3.7-9.1)$ & $<0.001$ \\
\hline $\begin{array}{l}\text { LYMPH } \\
\left({ }^{*} 10 \otimes / L\right)\end{array}$ & $\begin{array}{l}1.1- \\
3.2\end{array}$ & $1.4(1.0-1.8)$ & $1.1(0.8-1.4)$ & $<0.001$ & $1.1(0.8-1.5)$ & $0.9(0.6-1.3)$ & $<0.05$ \\
\hline PLT (10区/L) & $\begin{array}{l}125- \\
350\end{array}$ & $\begin{array}{l}\text { 196.0(151.5- } \\
239.3)\end{array}$ & $\begin{array}{l}213.0(162.0- \\
297.0)\end{array}$ & $<0.001$ & $\begin{array}{l}217.0(169.5- \\
286.5)\end{array}$ & $\begin{array}{l}211.5(153.5- \\
337.8)\end{array}$ & NS \\
\hline $\begin{array}{l}\text { NEUT / } \\
\text { LYMPH }\end{array}$ & NA & $3.1(2.1-4.6)$ & $3.7(2.2-5.9)$ & NS & $3.1(1.9-4.8)$ & $5.4(3.4-12.5)$ & $<0.001$ \\
\hline $\begin{array}{l}\text { PLT/ } \\
\text { LYMPH }\end{array}$ & NA & $\begin{array}{l}\text { 139.8(106.6- } \\
188.0)\end{array}$ & $\begin{array}{l}\text { 195.8(150.0- } \\
300.5)\end{array}$ & $<0.001$ & $\begin{array}{l}\text { 188.7(147.3- } \\
278.9)\end{array}$ & $\begin{array}{l}246.3(158.4- \\
384.7)\end{array}$ & $<0.01$ \\
\hline $\begin{array}{l}\text { Creatinine } \\
(\mu \mathrm{mol} / \mathrm{L})\end{array}$ & $57-97$ & $71.5(60.6-90.3)$ & $68.0(57.9-81.0)$ & $<0.05$ & $\begin{array}{l}69.0(59.7- \\
80.0)\end{array}$ & $\begin{array}{l}66.6(55.2- \\
85.3)\end{array}$ & NS \\
\hline $\begin{array}{l}\text { Glucose } \\
(\mathrm{mmol} / \mathrm{l})\end{array}$ & $\begin{array}{l}3.9- \\
6.1\end{array}$ & $5.2(4.8-5.8)$ & $6.0(5.2-7.7)$ & $<0.001$ & $5.8(5.1-7.0)$ & $6.9(5.4-8.6)$ & $<0.001$ \\
\hline CRP (mg/L) & $0-4$ & $1.3(1.0-2.6)$ & $21.5(4.9-68.5)$ & $<0.001$ & $18.8(3.6-54.5)$ & $\begin{array}{l}43.6(11.1- \\
157.7)\end{array}$ & $<0.001$ \\
\hline IL-6 (pg/nl) & $0-7$ & NA & $9.1(7.0-14.6)$ & NA & $8.6(7.1-13.2)$ & $\begin{array}{l}10.9(6.6- \\
18.9)\end{array}$ & NS \\
\hline $\begin{array}{l}\text { TC } \\
(\mathrm{mmol} / \mathrm{l})\end{array}$ & $\begin{array}{l}3.3- \\
5.2\end{array}$ & $4.8(4.1-5.4)$ & $3.9(3.4-4.4)$ & $<0.001$ & $3.9(3.4-4.4)$ & $3.8(3.2-4.6)$ & NS \\
\hline $\begin{array}{l}\text { TG } \\
(\mathrm{mmol} / \mathrm{l})\end{array}$ & $\begin{array}{l}0.5^{-} \\
1.7\end{array}$ & $1.2(0.8-1.9)$ & $1.3(0.9-1.7)$ & NS & $1.2(0.9-1.7)$ & $1.3(1.0-1.9)$ & NS \\
\hline $\begin{array}{l}\text { LDL-C } \\
(\mathrm{mmol} / \mathrm{l})\end{array}$ & $\begin{array}{l}2.1- \\
3.4\end{array}$ & $2.5(2.0-3.2)$ & $2.3(1.9-2.8)$ & $<0.05$ & $2.4(1.9-2.8)$ & $2.2(1.8-2.7)$ & NS \\
\hline $\begin{array}{l}\text { HDL-C } \\
(\mathrm{mmol} / \mathrm{l})\end{array}$ & $\begin{array}{l}1.3- \\
1.6\end{array}$ & $1.3(1.1-1.6)$ & $0.9(0.8-1.1)$ & $<0.001$ & $0.9(0.8-1.2)$ & $0.9(0.8-1.1)$ & NS \\
\hline $\begin{array}{l}\text { Non-HDL-c } \\
(\mathrm{mmol} / \mathrm{l})\end{array}$ & NA & $3.3(2.7-4.0)$ & $2.9(2.4-3.4)$ & $<0.001$ & $2.9(2.5-3.4)$ & $2.9(2.4-3.5)$ & NS \\
\hline apoA-I (g/l) & $1.0-1.6$ & $1.2(0.9-1.4)$ & $1.1(0.9-1.2)$ & $<0.001$ & $1.1(0.9-1.2)$ & $1.0(0.9-1.2)$ & NS \\
\hline apoB $(g / l)$ & $\begin{array}{l}0.6^{-} \\
1.1\end{array}$ & $0.8(0.7-1.0)$ & $0.9(0.8-1.0)$ & $<0.05$ & $0.9(0.7-1.0)$ & $0.9(0.8-1.1)$ & NS \\
\hline
\end{tabular}

Data are expressed as median (interquartile range) or $\mathrm{n}(\%)$. WBC, white blood cell; NEUT, neutrocytes LYMPH, lymphocytes; PLT, platelet; CRP, C-reactive protein; IL-6, interleukin-6; TC, total cholesterol; TG, triglyceride; LDL-C, low density lipoprotein cholesterol; HDL-c, high density lipoprotein cholesterol; Non-HDL-C, non-high density lipoprotein cholesterol; apoA-l, apolipoprotein A-l; apoB, apolipoprotein B; Lp(a), lipoprotein(a). NS, not significant; NA, not applicable. 


\begin{tabular}{|c|c|c|c|c|c|c|c|}
\hline & $\begin{array}{l}\text { Normal } \\
\text { Range }\end{array}$ & $\begin{array}{l}\text { Control } \\
(n=242)\end{array}$ & $\begin{array}{l}\text { All patients } \\
(n=242)\end{array}$ & $\begin{array}{l}P \text { for the } \\
\text { comparison } \\
\text { of patients } \\
\text { with } \\
\text { controls }\end{array}$ & $\begin{array}{l}\text { Non severe } \\
\text { group } \\
(n=173)\end{array}$ & $\begin{array}{l}\text { Severe group } \\
(n=69)\end{array}$ & $\begin{array}{l}P \text { for the } \\
\text { comparison } \\
\text { of } \\
\text { moderate } \\
\text { and severe } \\
\text { patients }\end{array}$ \\
\hline apoB/apoA- & NA & $0.7(0.5-1.0)$ & $0.9(0.7-1.1)$ & $<0.001$ & $0.8(0.6-1.1)$ & $0.9(0.7-1.1)$ & NS \\
\hline $\begin{array}{l}\operatorname{Lp}(a) \\
(\mathrm{mg} / \mathrm{l})\end{array}$ & $0-300$ & NA & $\begin{array}{l}131.8(63.2- \\
274.3)\end{array}$ & NA & $\begin{array}{l}131.2(57.7- \\
267.7)\end{array}$ & $\begin{array}{l}156.7(65.9- \\
300.9)\end{array}$ & NS \\
\hline
\end{tabular}

There were notable positive correlations between CRP levels and total neutrocytes (rho $=0.457, P<0.001$ ), CRP and neutrocyte/lymphocyte ratio ( $r h o=0.636, \mathrm{P}<0.001)$. We also observed an inverse correlation between $\mathrm{CRP}$ and total lymphocytes (rho $=-0.539, P<0.001)$. In addition, the total lymphocytes were weakly positively associated with TC (rho $=0.271, P<0.001)$, LDL-C (rho $=0.319, P<0.001)$ and apoA-I (rho $=0.194, P<0.01)$ (Fig. 1).

\section{Inflammatory markers and lipid profiles}

In the Covid-19 patients, the elevated CRP levels were inversely associated with TC (rho $=-0.244, P<0.001)$, LDL-C (rho $=-0.288, P<$ $0.001)$, HDL-c (rho $=-0.191, P<0.01)$, non-HDL-c (rho $=-0.205, P<0.001)$ and apoA-I (rho $=-0.361, P<0.001)$, but positively associated with apoB/apoA-I ratio (rho $=0.242, P<0.001)$ (Fig. 2). The IL-6 levels were also weakly negatively associated with $\mathrm{TC}$ (rho $=-0.188$, $P<0.05)$, apoA-I (rho $=-0.154, P<0.05)$ and apoB (rho $=-0.154, P<0.05)$. No significant correlations between the levels of erythrocyte sedimentation rate (ESR) and the values of lipid or lipoprotein were found. We also observed patients with elevated PCT levels (> $0.05 \mathrm{ng} / \mathrm{ml}$ ) have lower levels of TC(3.9 IQR 3.4-4.4 Vs. 4.0 IQR 3.6-4.5 mmol/I, $P<0.01)$, LDL-c(2.3 IQR 1.0-2.8 Vs. 2.5 IQR 2.1$2.9 \mathrm{mmol} / \mathrm{l}, P<0.001)$, HDL-c(0.9 IQR 0.8-1.1 Vs. 1.0 IQR 0.8-1.2 mmol/I, $P<0.01)$, non-HDL-c(2.8 IQR 2.3-3.4 Vs. 3.1 IQR 2.6$3.5 \mathrm{mmol} / \mathrm{I}, P<0.05)$, apoA-I (1.0 IQR 0.8-1.1 Vs. 1.1 IQR 0.9-1.3 g/l, $P<0.001)$ than the normal PCT patients.

\section{Discussion}

To the best of our knowledge, this is the first preliminary study descriptively evaluating the effects of global pandemic Covid-19 on the lipoprotein profiles. The TC, HDL-C, LDL-C, non-HDL-C and apoA-I were reduced while apoB/apoA-I ratio increased after Covid-19 infection, while there were no differences in lipid or lipoprotein levels in the severe patients compared with the moderate group. Given that the epidemic situation of Covid-19 infection is becoming more and more serious all over the world and is shedding more and more threats on human beings, this timely study provides important data on the lipid and lipoprotein changes observed in this setting.

Previous studies report that various viral infections, including EBV, Dengue virus and influenza A are associated with lower cholesterol levels [9-11]. Since all the Covid-19 patients developed hypocholesterolemia in our study, and the changes in lipoproteins were equal among the moderate and severe groups, all of those suggests it was a nonspecific response to acute viral infections. In addition, we found the increased inflammatory markers (CRP, IL-6) on admission were inversely correlated with lipid and lipoprotein levels, suggesting that the possible common mechanism for hypocholesterolemia in acute viral infections was inflammatory processes. IL-6 released from the immunocytes stimulates LDL receptor expression in hepatocytes and subsequently lead to increased LDL uptake and decreased LDL-c levels [12]. The cytokines influence the activities essential for lipoprotein mature and metabolism in the circulation and further reform the lipoproteins. A decrease in lecithin:cholesterol acyltranferase activity could decrease HDL-c concentration and the enhanced cholesteryl ester transfer protein activity further decreased HDL-c and increased TG levels. Consistent with the decreased lipoprotein levels, the lipoproteins lost its physiological functions and become more atherogenic after inflammatory stimulation. The cytokines reversibly remodel the LDL to smaller particles (small-dense LDL) and predisposed to oxidization in the arterial wall and become more atherogenic. ${ }^{4}$ We failed to observe the differences in lipid and lipoproteins among the moderate and sever groups, one possible reason is that a cytokine storm was exhibited in nearly all these 
populations and exhaust the anti-inflammatory properties of lipids [13]. Moreover, rather than simply affected by the viral infection, the lipid system has been reported to engaged in pathological process of viral infection, subsequent immune response and inflammatory activation. The HCV virions and dengue virus may fuse with premature very low-density lipoproteins (VLDL) and form a lipoviroparticle with VLDL particles, thus enabling it to circulate throughout the body as normal lipoproteins and then follow entry host cell by the LDL receptor [14-16].

We also observed a marked decrease in serum levels of HDL-c and apoA-I in Covid-19 patients. Previous studies have found that HDL and apoA-l in the setting of cytokine storm further lost their function in cholesterol efflux, anti-oxidative, anti-inflammatory, antiapoptotic, and vasoprotective effects. The decreased HDL-associated enzyme paraoxonase1 (PON1) further exacerbate the oxidative modifications in LDL. We also observed that consistent with the decrease in apoA-I and increase in apoB, the apoB/apoA-1 ratio, which worked as indices for risk of acute myocardial infarction, were notable increased. In addition, both the CRP and IL- 6 are negatively associated with apoA-1 levels, suggesting that the protein components are superior to reflect the anti-inflammatory properties of HDL. All together, the comprehensive changes in lipid and lipoprotein levels and proatherogenic functions may partly explain the observed phenomenon of increase in heart attack and stroke after Covid-19 infection and the mortality were significantly higher among the patients with circulatory comorbidities (including hypertension and coronary heart diseases) [17].

Proper inflammation plays a critical role in an effective immune response, while exuberant inflammatory responses cause damage to extrapulmonary tissues and organs. The cytokine and inflammation driven atherogenic lipid profiles after Covid-19 infection could be a therapeutic target for pneumonia and extrapulmonary organ protection. The corticosteroids were most frequently prescribed in order to reduce inflammatory-induced lung injury in patients with severe acute respiratory syndrome (SARS) and Middle East respiratory syndrome (MERS). However, evidence from patients with SARS and MERS and early experience from Covid-19 patients in Wuhan, China suggest that corticosteroids treatment failed to reduce mortality, but rather delayed viral clearance and induced sequelae such as femoral head necrosis [18-19]. D-4F, synthetic apoA-I mimetic peptides, were reported to restore the decreased HDL-c and PON activity in animal models of influenza pneumonia. In addition, D-4F administration suppress virus-induced cytokine production and reduces viral titers in lungs, resulting in alleviated lung injury [20]. As an emerging virus, an effective treatment especially the antiviral treatment for Covid-19 infection has not been developed except extensive supportive care [3], new options for treatment should be considered urgently in recent Covid-19 research. Thus, HDL and apoA-I, together with other lipids, may have a predictive role in Covid-19 induced cytokine storm, potentially becoming a new therapeutic target.

The main limitation of the study is the fact that we did not measure the lipid levels after the complete resolution (eg. 3-4 months after discharge) of febrile illness due to the outbreaks of the disease. Second, because data regarding the viral load are not available, further studies are needed to investigate the correlation between the viral load, cytokine storm and lipid levels.

\section{Conclusions}

Patients with Covid-19 exhibit atherogenic lipid changes which might be correlated with exuberant inflammatory responses. Gaining a deeper understanding of the factors that affect lipids in patients with Covid-19 and its clinical significance, is of importance for Covid-19 management.

\section{Declarations}

\section{Acknowledgments}

We respectfully and sincerely thank all front-line medical staff around the globe for hard work and sacrifice, racing to save life and contain the spread.

\section{Authors' contributions}

$\mathrm{CL}, \mathrm{WZ}$ and $\mathrm{CZ}$ conceived and designed the study. $\mathrm{XZ}$ and $\mathrm{CL}$ were responsible for the formal analyses. $\mathrm{CZ}$ and $\mathrm{GW}$ were responsible for the funding acquisition. $C L, C X, G C, L L, G W, M H, S W$ and QL had roles in patient management and data collection. HT did the statistical analysis, QS and LL contributed to the data presentation and interpretation. CL and WZ wrote the original draft, XZ and CZ were responsible for the review and editing. All authors read and approved the final manuscript.

Page $7 / 11$ 


\section{Funding}

This work was supported by grants from the National Natural Science Foundation of China (81600343) and National Basic Research Program of China (2013CB531104). This research also received supports from Program of Innovative Research Team by National Natural Science Foundation (81721001).

\section{Availability of data and materials}

The datasets used and/or analyzed during the current study are available from the corresponding author on request.

\section{Ethics approval and consent to participate}

The Ethics Commission of Third Military Medical University approved this study. Written informed consent was waived due to the rapid emergence of this infectious disease.

\section{Consent for publication}

Not applicable

\section{Competing interests}

The authors declare that they have no competing interests.

\section{Author details}

${ }^{1}$ Department of Cardiology, Daping Hospital, Third Military Medical University, Chongqing 400037, P.R. China. ${ }^{2}$ Infection Division, Wuhan Jin-yin-tan Hospital, Wuhan 430030, P.R.China. ${ }^{3}$ Infection Division, Wuhan Huo-shen-shan Hospital, Wuhan 430030, P.R.China. ${ }^{4}$ Institute of Respiratory Diseases, Department of Pulmonary and Critical Care Medicine, Xinqiao Hospital, Third Military Medical University, Chongqing 400037, P.R.China. ${ }^{5}$ Department of Cardiology, Xinqiao Hospital, Third Military Medical University, Chongqing 400037, P.R.China. ${ }^{6}$ Department of Pulmonary and Critical Care Medicine, Daping Hospital, Third Military Medical University, Chongqing 400037, P.R.China. ${ }^{7}$ Department of Medicine and Medical Research, Daping Hospital, Third Military Medical University, Chongqing 400037, P.R.China. ${ }^{8}$ Department of General Surgery, Daping Hospital, Third Military Medical University, Chongqing 400037, P.R.China. ${ }^{9}$ State Key Laboratory of Trauma, Burns and Combined Injury, Daping Hospital, The Third Military Medical University, Chongqing, 400042, P.R. China

\section{References}

1. World Health Organization (WHO). Coronavirus disease (COVID- 2019) situation reports, https://www.who.int/emergencies/diseases/novel-coronavirus-2019/situation-reports June 23, 2020.

2. Wang D, Hu B, Hu C, Zhu F, Liu X, Zhang J, et al. Clinical Characteristics of 138 Hospitalized Patients With 2019 Novel Coronavirus-Infected Pneumonia in Wuhan, China. JAMA.2020;323(11):1061-9.

3. Jin YH, Cai L, Cheng ZS, Cheng H, Deng T, Fan YP, et al. Evidence-Based Medicine Chapter of China International Exchange and Promotive Association for Medical and Health Care (CPAM). A rapid advice guideline for the diagnosis and treatment of 2019 novel coronavirus (2019-nCoV) infected pneumonia (standard version). Mil Med Res. 2020;7(1):4.

4. Bäck M, Yurdagul A Jr, Tabas I, Öörni K, Kovanen PT. Inflammation and its resolution in atherosclerosis: mediators and therapeutic opportunities. Nat Rev Cardiol. 2019;16(7):389-406.

5. Apostolou F, Gazi IF, Lagos K, Tellis CC, Tselepis AD, Liberopoulos EN, et al. Acute infection with Epstein-Barr virus is associated with atherogenic lipid changes. Atherosclerosis. 2010;212(2):607-13.

6. Fleck-Derderian S, McClellan W, Wojcicki JM. The association between cytomegalovirus infection, obesity, and metabolic syndrome in U.S. adult females. Obesity (Silver Spring). 2017;25(3):626-33.

7. Gordon EM, Figueroa DM, Barochia AV, Yao X, Levine SJ. High-density Lipoproteins and Apolipoprotein A-I: Potential New Players in the Prevention and Treatment of Lung Disease. Front Pharmacol. 2016;7:323. 
8. Link to report: National Health Commission. Diagnosis and treatment of pneumonia caused by 2019-nCoV (trial version 7). http://www.nhc.gov.cn/yzygj/s7653p/202003/46c9294a7dfe4cef80dc7f5912eb1989.shtml. Accessed 3 Mar 2020.

9. Zhang J, Du R, Peng K, Wu X, Hu C, Li M, et al. Serum lipoprotein (a) is associated with increased risk of stroke in Chinese adults: A prospective study. Atherosclerosis. 2019;289:8-13.

10. Biswas HH, Gordon A, Nuñez A, Perez MA, Balmaseda A, Harris E. Lower Low-Density Lipoprotein Cholesterol Levels Are Associated with Severe Dengue Outcome. PLoS Negl Trop Dis. 2015;9(9):e0003904.

11. Van Lenten BJ, Wagner AC, Anantharamaiah GM, Garber DW, Fishbein MC, Adhikary L, et al. Influenza infection promotes macrophage traffic into arteries of mice that is prevented by $D-4 F$, an apolipoprotein A-I mimetic peptide. Circulation. 2002;106(9):1127-32.

12. Gierens $H$, Nauck M, Roth $M$, Schinker R, Schürmann $C$, Scharnagl H, et al. Interleukin-6 stimulates LDL receptor gene expression via activation of sterol-responsive and Sp1 binding elements. Arterioscler Thromb Vasc Biol. 2000;20(7):1777-83.

13. Chen G, Wu D, Guo W, Cao Y, Huang D, Wang H, et al. Clinical and immunological features of severe and moderate coronavirus disease 2019. J Clin Invest. 2020;130(5):2620-29.

14. Agnello V, Abel G, Elfahal M, Knight GB, Zhang QX. Hepatitis $C$ virus and other flaviviridae viruses enter cells via low density lipoprotein receptor. Proc Natl Acad Sci U S A. 1999;96(22):12766-71.

15. André P, Komurian-Pradel F, Deforges S, Perret M, Berland JL, Sodoyer M, et al. Characterization of low- and very-low-density hepatitis C virus RNA-containing particles. J Virol. 2002;76(14):6919-28.

16. Faustino AF, Carvalho FA, Martins IC, Castanho MA, Mohana-Borges R, Almeida FC, et al. Dengue virus capsid protein interacts specifically with very low-density lipoproteins. Nanomedicine. 2014;10(1):247-55.

17. Guan WJ, Liang WH, Zhao Y, Liang HR, Chen ZS, Li YM, et al. Comorbidity and its impact on 1590 patients with COVID-19 in China: a nationwide analysis. Eur Respir J. 2020;55(5):2000547.

18. Huang C, Wang Y, Li X, Ren L, Zhao J, Hu Y, et al. Clinical features of patients infected with 2019 novel coronavirus in Wuhan, China. Lancet. 2020;395(10223):497-506.

19. Zhao R, Wang H, Wang X, Feng F. Steroid therapy and the risk of osteonecrosis in SARS patients: a dose-response metaanalysis. Osteoporos Int. 2017;28(3):1027-34.

20. Van Lenten BJ, Wagner AC, Anantharamaiah GM, Garber DW, Fishbein MC, Adhikary L, et al. Influenza infection promotes macrophage traffic into arteries of mice that is prevented by D-4F, an apolipoprotein A-I mimetic peptide. Circulation.

2002;106(9):1127-32.

\section{Figures}



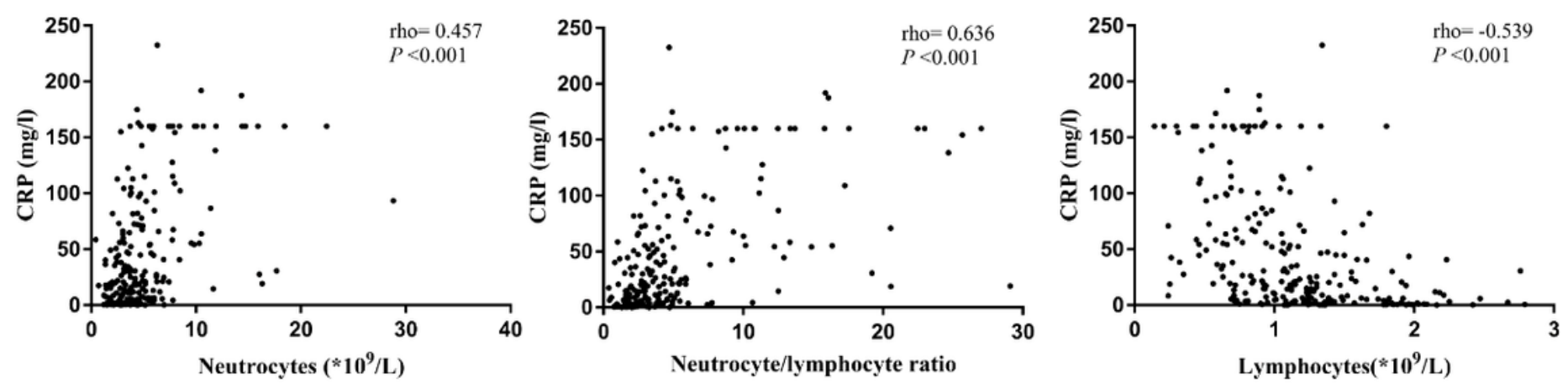

D

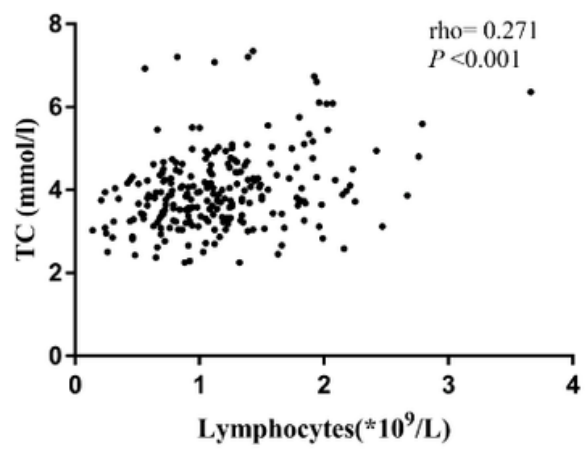

$\mathrm{E}$

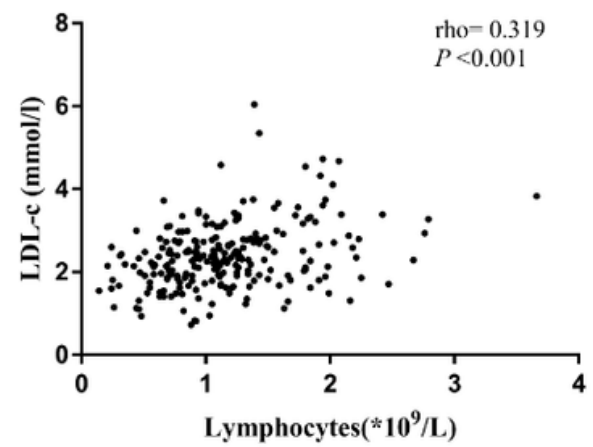

$\mathrm{F}$

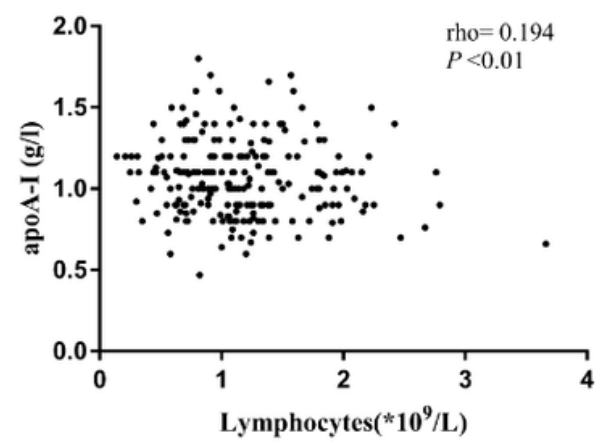

Figure 1

Association of the CRP and lipid levels with dysregulation of blood lymphoid and myeloid cells in Covid-19 patients. A Correlations between CRP levels at admission with total neutrocytes. B Correlations between CRP levels at admission with neutrocyte/lymphocyte ratio. C Correlations between CRP levels at admission with total lymphocytes. D Correlations between total lymphocytes with TC. E Correlations between total lymphocytes with LDL-c. F Correlations between total lymphocytes with apoA-I. TC, total cholesterol; LDL-C, low density lipoprotein cholesterol; apoA-I, apolipoprotein A-I.The Spearman's test was used to evaluate the correlation. Each symbol represents an individual participant $(\mathrm{N}=242)$. P values $<0.05$ were considered significant. 
A

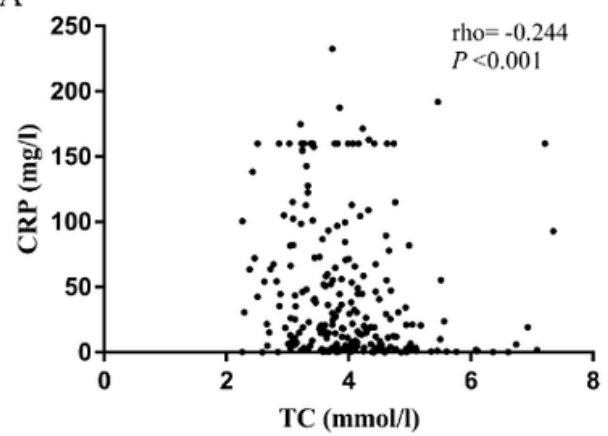

D

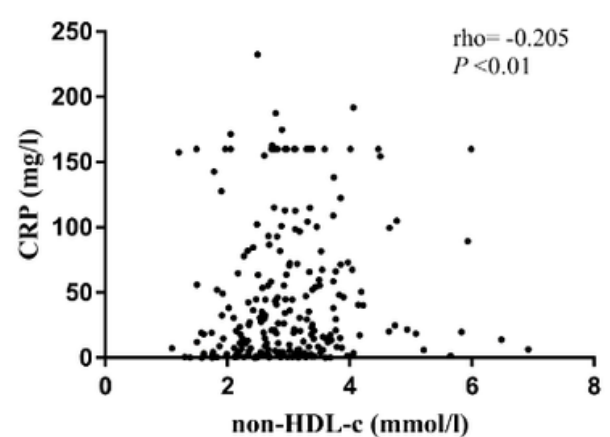

B

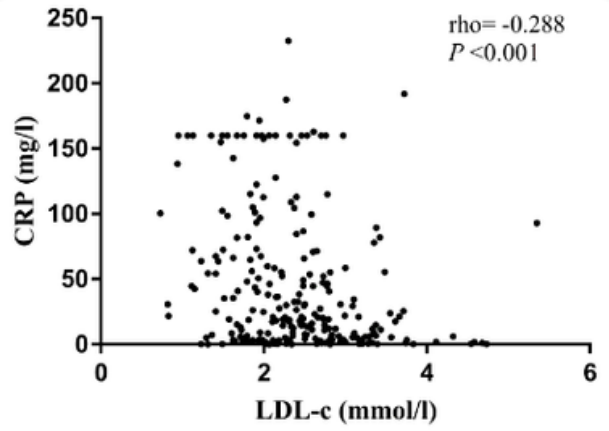

E

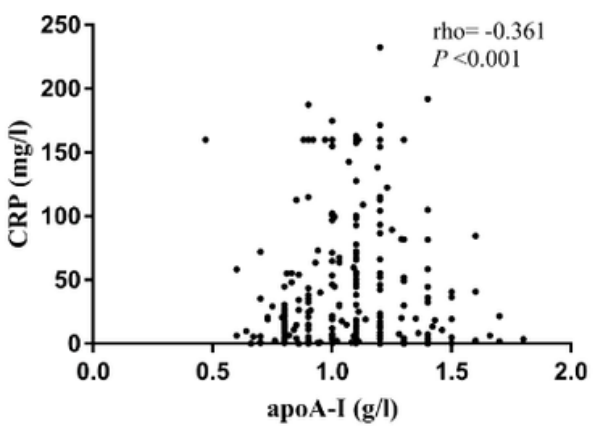

$\mathrm{C}$

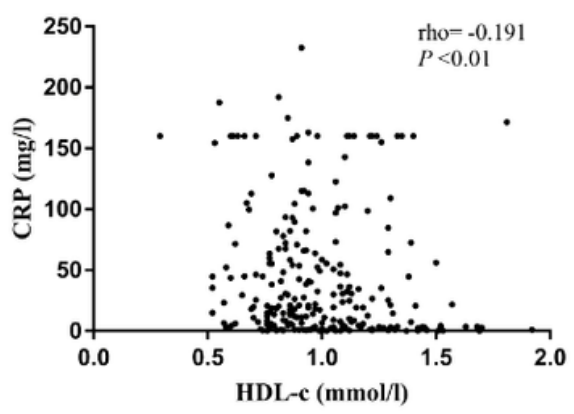

$\mathrm{F}$

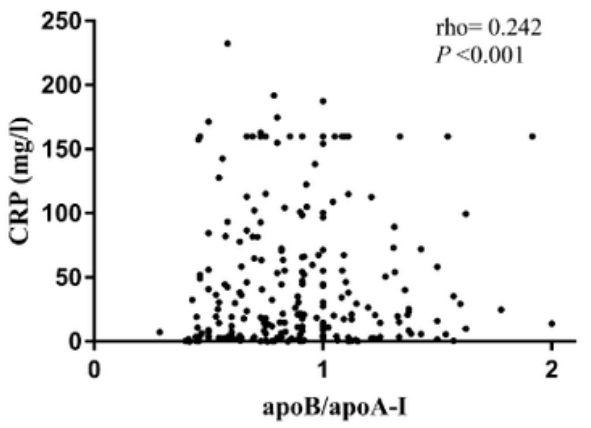

Figure 2

Association of the CRP levels with lipids and lipoproteins in Covid-19 patients. Correlations between CRP levels at admission with TC $(A)$, LDL-c (B), HDL-c (C), non-HDL-c (D), apoA-I (E), apoB/apoA-I (F). The Spearman's test was used to evaluate the correlation. Each symbol represents an individual participant $(N=242)$. $P$ values $<0.05$ were considered significant. 